\title{
Physical Factors Influencing FVC in Indian Adult Males
}

\author{
Chandrashekhar D.M'1, Anandkumar ${ }^{1}$, Jayalakshmi.M.K², Prashanth Babu ${ }^{3}$ \\ ${ }^{1}$ Assistant Professor, ${ }^{2}$ Professor, ${ }^{3}$ AssociateProfessor, Department of Physiology, \\ Gadag Institute of Medical Sciences, Gadag, Karnataka, India
}

\begin{abstract}
Background: Pulmonary function tests are widely used as a valuable diagnostic tool in detecting and diagnosing various respiratory disorders like COPD, they also play an important role in monitoring therapy effectiveness and course of the disease. Normative values of pulmonary functions of healthy population are affected by different geographic, ethnic, climatic and demographic factors. The most important determining factors of Vital capacity in an individual are anthropometric factors such as age, sex, height, weight, body mass index (BMI) and body surface area (BSA)
\end{abstract}

Aims and Objectives: The aim of the present study was to find the correlation between Forced Vital Capacity (FVC) and anthropometric measurements like height, weight, body mass index (BMI) and body surface area (BSA) in Indian adult males.

Materials and Method: Fifty healthy adult males were randomly selected for the study. Ethical clearance was taken from the Institutional Ethical Committee. The physical factors namely height, weight, body mass index (BMI), and body surface area (BSA) were measured. FVC was recorded by using computerized spirometer. The correlation between the various physical factors and FVC was done using Pearson's correlation.

Results: Height, weight and body surface area showed significant positive correlation with FVC. However height showed the strongest correlation $(\mathrm{r}=0.5807)$, followed by BSA $(\mathrm{r}=0.531)$ and lastly weight $(\mathrm{r}=$ 0.422). However the correlation of BMI with FVC was not statistically significant.

Conclusion: The present study showed that body height, body surface area and body weight are important determinant of FVC in Indian adult males, with height being the most important determinant.

Keywords: FVC, height, weight, BMI, Body Surface Area.

\section{Introduction}

Pulmonary function test (PFT) is the comprehensive evaluation of the respiratory system in an individual. In a clinical setting, the primary purpose of pulmonary function testing is to identify the severity of pulmonary impairment in various respiratory disorders, mainly chronic obstructive pulmonary disease (COPD). ${ }^{1}$

\section{Corresponding author.}

Anandkumar

Assistant Professor, Department of Physiology

Gadag Institute of Medical Sciences

Gadag, Karnataka, India, Ph: 8971282391

Email: dranandhugar01@gmail.com
Pulmonary function tests provide objective, quantifiable measures of lung function, which are valuable in evaluating and monitoring diseases that affect both the heart and lung function. They are also useful to monitor the effects of environmental, occupational, and drug exposures, to assess risks of surgery, and to assist in routine health evaluations performed before employment. ${ }^{2}$ During last few decades, PFTs have evolved from being used as tool for physiological study to an indispensable clinical investigation in assessing respiratory status of the patients.

The development of pulmonary functions in an individual coexists with the growth of physical parameters i.e. body height and body weight. These 
physical parameters are further affected by nutrition and physical activities of growing children. ${ }^{3}$ The development of pulmonary function and growth of physical parameters go hand in hand in children. ${ }^{4}$

Obese and overweight people are at a higher risk of respiratory symptoms, such as breathlessness, particularly during exercise, even if they have no obvious respiratory illness. The association between obesity and asthma leads one to question whether the mechanical effects of obesity on the respiratory system could contribute to airway dysfunction that may induce or worsen asthma. ${ }^{5}$

Age has historically been one of the major factors influencing lung function. Pulmonary maturity is reached at about 20-25 years of age, ${ }^{6}$ after which lung function progressively begins to decline. ${ }^{7}$ Several parameters such as Total Lung Capacity (TLC), FVC and Forced Expiratory volume at one second (FEV1), are affected by height, and they are proportional to body size. ${ }^{8}$ This means that in tall individuals, who accordingly have greater lung capacity, lung volume will decrease at a greater rate compared to shorter individuals as they grow older. ${ }^{9}$ Obesity can cause airway limitation, causing a parallel reduction in FEV1 and $\mathrm{FVC}$, thus preserving the FEV1/FVC ratio. ${ }^{10}$ Abdominal obesity is generally associated with reduced FEV1 and FVC in women and in certain age groups. ${ }^{11}$

Spirometry is the measurement of air moving in and out of the lungs during various respiratory maneuvers. It plays a pivotal role in the diagnosis and monitoring of patients with respiratory disease. ${ }^{12}$ Spirometry is easier to perform and even patients with heart and lung diseases can perform it, when instructed properly by well-trained technician and or other health care provider.

The prevalence of childhood pulmonary diseases especially bronchial asthma is increasing worldwide and this necessitates the need for establishing regression equations for predicting pulmonary function in children. ${ }^{13}$

The present study is undertaken to find out which of the physical factors of an individual best correlates with FVC.

\section{Materials and Method}

This is a cross sectional study, which was carried out in the Research laboratory, Department of Physiology, KVG Medical College, Sullia. The study and its conduct were cleared by the ethical committee of the same Institute. Fifty male adult non smokers were randomly selected from population of Sullia taluk. Informed consent was obtained from every subject.

\section{Inclusion Criteria:}

1) Male subjects in age group of 18 to 30 years.

\section{Exclusion Criteria:}

1) History of cardiovascular diseases.

2) History of chronic obstructive pulmonary diseases and chronic restrictive lung diseases.

3) Smokers

\section{Methods of collection of Data:}

- Health status was obtained by comprehensive Questionnaires.

- Body height was measured using wall mounted stadiometer.

- Body Weight was recorded with portable weighing machine

- BMI was calculated as per formula: Weight (Kg)/Height (meter) ${ }^{2}$. formula.

- Body surface area is calculated as per Dubois

$$
\text { BSA }=0.007184 \times \text { Weight }^{0.425} \times \text { Height }^{0.725}
$$

Computerized data logging Spiro meter was used for recording the pulmonary function tests (UNI-EM Spiromin 6.24.9 Ink)

Vital parameters like pulse rate, BP were also recorded.

\section{Statistical Analysis}

The correlation between body height, body weight, BMI and BSA with FVC was done using Pearson's correlation coefficient. All the analysis was done by using SPSS-20 software. 


\section{Findings}

Table 1: Mean anthropometric measurements and FVC Of subjects

\begin{tabular}{|l|l|}
\hline Parameter & Mean \pm SD \\
\hline FVC(litres) & $3.95 \pm 0.61$ \\
\hline Height(centimetres) & $171.4 \pm 7.12$ \\
\hline Weight(kgs) & $66.12 \pm 11.71$ \\
\hline BMI(kg/m2) & $22.42 \pm 3.15$ \\
\hline Body surface area(m2) & $1.77 \pm 0.16$ \\
\hline
\end{tabular}

Table 2: Correlation of various anthropometric measurements with FVC

\begin{tabular}{|l|l|l|}
\hline Parameters & 'r' value & P value \\
\hline Height & 0.58 & 0.00001 \\
\hline Weight & 0.422 & 0.002 \\
\hline BMI & 0.19 & 0.186 \\
\hline Body surface area & 0.53 & 0.00007 \\
\hline
\end{tabular}

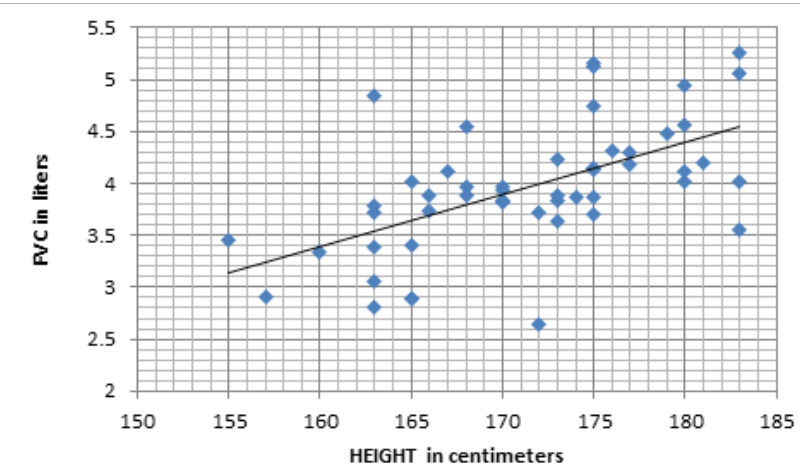

Graph 1: Correlation of body height with FVC

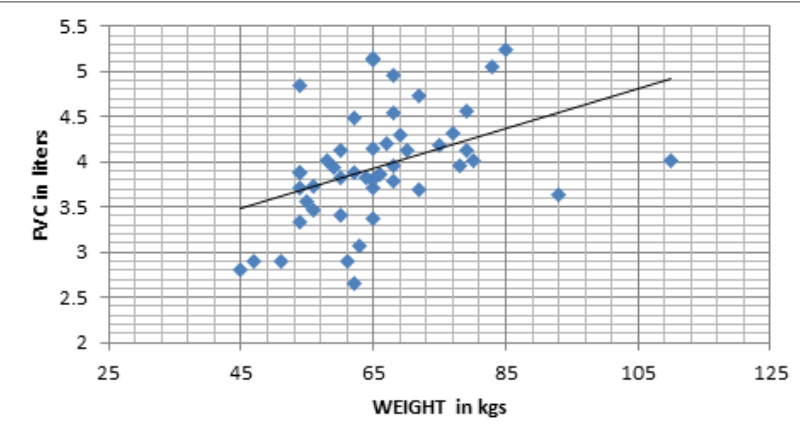

Graph 2: Correlation of body weight with FVC

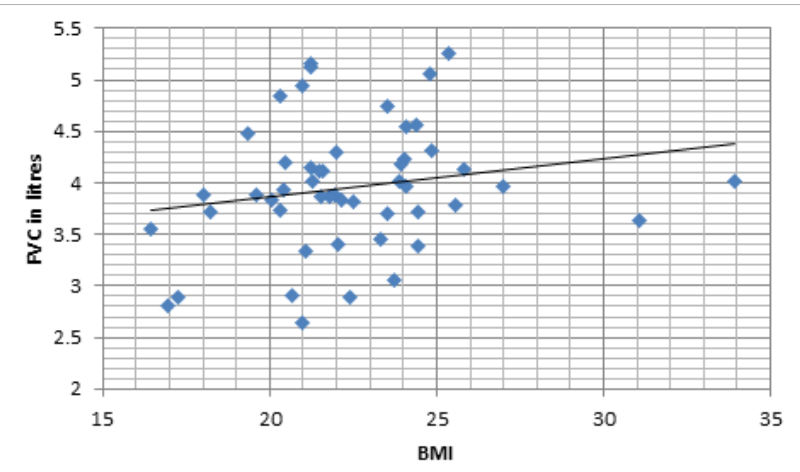

Graph 3: Correlation of BMI with FVC

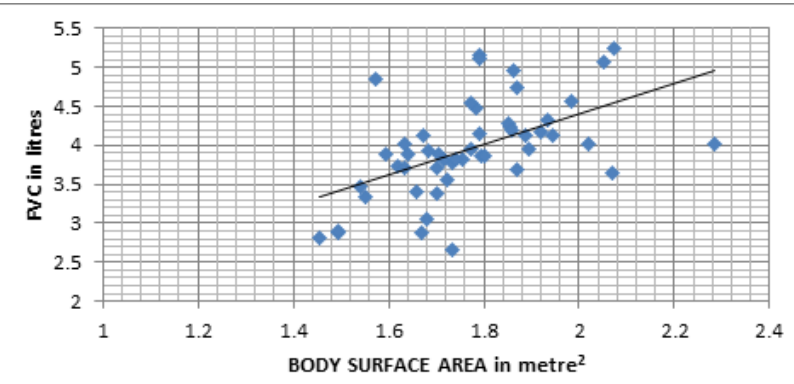

Graph 4: Correlation of BSA with FVC

\section{Discussion}

The main objective of this study was to investigate the relationship between the lung function parameter FVC and selected anthropometric variables, which included body height, body weight, BMI and Body surface area.

The present study aimed to explore the influence of anthropometric measurements on FVC. In the present study three physical factors showed significant correlation with FVC, body height showed the strongest correlation $(\mathrm{r}=0.5807)$, followed by BSA $(\mathrm{r}=0.531)$ and lastly body weight $(r=0.422)$ and BMI showed no statistically significant correlation with FVC.

Results of pulmonary function are influenced by many factors: gender, stature, race, age, technical factors, weight, and others. ${ }^{14}$ The relationship between body size and spirometry values also changes with age. ${ }^{15}$

Thoracic dimensions grow more in length than in width. ${ }^{16}$ A similar study done by Carel $\mathrm{R} \mathrm{S}$ et al., in young navy selectees showed that thoracic perimeter and body height are the best predictors for forced vital capacity and $\mathrm{FEV}_{1 .}{ }^{17}$

In our study it was observed that body height, body weight and body surface area were found to be positively correlated to FVC, the findings were similar to a study 
done by Sachin Pawar et al. ${ }^{18}$

A similar study done by Muralidhara and Bhat, in underweight and overweight subjects, found no correlation between BMI, body fat percentage and the pulmonary functions, which concur with the present study. ${ }^{19}$

The present study showed that height was the most important determinant of FVC, which concurs with a similar studies..$^{20,21}$

Aundhakar et al. established a positive correlation between pulmonary function like FVC, Maximum voluntary ventilation, Peak expiratory flow rate and anthropometric parameters like age, height, weight, BSA, BMI etc. ${ }^{22}$

According to the American College of Sports Medicine, due to increased weight on the chest wall and diaphragm obesity has mechanical effects on respiration. Being obese also causes an increase in energy use as compared to a leaner person at the same workload, so in heavier people the respiratory muscles fatigue at lower intensities. These effects may contribute to the decreases in Functional Residual Capacity, Expiratory Reserve Volume and Total Lung Capacity. But in our study there is no correlation between FVC and BMI in young males. ${ }^{23}$

A study done by Chatterjee et al., reported that FVC, FEV1 and PEFR values increased progressively with age from 9 to 16 years and showed significantly high correlation coefficient with weight and negative correlation of FEV1 \% with body surface area. ${ }^{24}$

Height is considered as better index of body size and body size is proportional to lung size. This might be the reason for its best correlation with PFTs.$^{25}$

There are a few studies which however differ from the results of the present study, in some studies BSA showed less correlation than weight and in some studies height was not the primary determinant. ${ }^{26,27}$

Many of recent studies have observed that pulmonary function shows an inverse relationship with various markers of obesity and fat distribution in children and adolescent. ${ }^{28}$

Markers of both general and visceral obesity like BMI, Waist circumference and Waist hip ratio are reported to influence pulmonary function in children and adolescent. Some of the recent studies showed that respiratory mechanics can be affected by fat distribution pattern and central obesity, estimated by Waist circumference and Waist hip ratio independent of BMI. ${ }^{29}$

Our study has shown strong positive correlation of FVC with body height followed by BSA and body weight. But BMI has no correlation with FVC, better obesity markers like WC, WHR to be taken to study the effect of obesity on lung functions.

\section{Conclusion}

In conclusion, our study showed body height, body surface area and body weight are the strong determinants of pulmonary function test FVC compared to BMI. BMI showed no statistically significant correlation with FVC in the present study. We conclude that physical factors have a strong influence in determining FVC, and hence these should be taken into account while standardizing the predictive values of PFT.

Limitation The sample size was fifty; future studies can include a larger sample size for accurate predictions. The measure of obesity in the present study was BMI; future studies can include other measures of obesity, especially measures of central obesity like waist circumference and waist hip ratio for better results.

Funding: Self funded.

Conflict of Interest: None declared.

Ethical approval: The study was approved by the Institutional Ethics Committee.

\section{References}

1. Pulmonary terms and symbols: a report of the ACCP-ATS Joint Committee on Pulmonary Nomenclature, Chest 1975; 67:583

2. Robert o. Crapo. Pulmonary function testing. N. Engl J Med 1994; 331:25-30

3. Jiwtode MT, Raikar PR. Comparison of pulmonary function tests in urban and rural children of Nagpur, Maharashtra, India. Int J Res Med Sci. 2017; 5(3):908-11.

4. Deshpande JN, Dahat HB, Shirole CD, Pandc AH, et al. Pulmonary function and their correlation with anthropometric parameters in rural children. Indian J Pediatrics. 1983; 50:375-8.

5. Lad UP, Vilas G. Correlation between Body Mass 
Index (BMI), Body Fat Percentage and Pulmonary Functions in Underweight, Overweight and Normal Weight Adolescents. J Clinical Diagnosis Res. 2012; 6(3):350-3.

6. Sharma G, Goodwin J. Effect of aging on respiratory system physiology and immunology. Clinical Intervention and Aging. 2006; 1:253-60.

7. Lee B, Park S, Han D. Analysis of the influential factors of maximal-effort expiratory capacity of elderly women. J Phys Ther Sci. 2016;28:2924-8

8. Quanjer PH, CapderouA, Mazicioglu MM,AggarwalAN, Banik SD, Popovic S, et al. All-age relationship between arm span and height in different ethnic groups. Eur Respir J. 2014; 44:905-12.

9. Rufino R, Costa CH, Lopes AJ, Maiworm AI, Maynard K, Silva LM, et al. Spirometry reference values in the Brazilian population. Braz J Med Biol Res. 2017; 50:5700.

10. McCallister JW, Adkins EJ, O'Brien JM. Obesity and acute lung injury. Clin Chest Med. 2009; 30:495-508.

11. Ochs-Balcom HM, Grant BJ, Muti P, Sempos CT, Freudenheim JL, Trevisan M, et al. Pulmonary function and abdominal adiposity in the general population. Chest. 2006; 129:853-62.

12. Golshan M, Nematbakhsh M, Amra B and Crapo RO. Spiro metric reference values in a large Middle Eastern population. European Respir J 2003; 22(3):529-534

13. Mitchell EA. International trend in hospital admission rates for asthma. Arch Dis Child. 1985; 60:376-8.

14. Polgar C, Promadhat V. Standard values. In: Pulmonary function testing in children: techniques and standards. $1^{\text {st }}$ ed. Philadelphia: WB Saunders, 1971; 87-122.

15. Polgar GJ, Weng TR. The functional development of the respiratory system. Am Rev Respir Dis 1979; 120:625-95.

16. Degroodt EG, Van Peit W, Borsboom GJJM, Quanjer PH, van Zomeren BC. Growth of lung and thorax dimensions during the pubertal growth spurt. Eur Respir J 1988; 1:102-8.

17. Carel RS, Greenstein A, Ellender E, Melamed Y, Kerem D. Factors affecting ventilatory lung function in young navy selectees. Am Rev Respir
Dis 1983; 128:249-52.

18. Pawar S, Taksande AB. Prediction of pulmonary norms in healthy school boys 5-15 years - A review article. J Mahatma Gandhi Institute Med Sci. 2011; $16(1)$.

19. Muralidhara DV, Bhat MR. Some aspects of the pulmonary functions in underweight and overweight human subjects. Thai J Physiological Sci. 2007; 20:3-7.

20. Vijayan VK, Reetha AM, Kuppurao KV, Venkatesan P, Thilakavathy S. Pulmonary function in Normal South Indian children aged 7-19 years. Indian J Chest Dis Allied Sci. 2000; 42: 147-156.

21. Tasi MC, Jeng MJ, Chang HL, Taso PC, Yang CF, Peng YY, et al. Spiro metric reference equations for healthy children aged 6 to 11 years in Taiwan. J Chin Med Assoc 2010; 73:218.

22. C.D.Aundhakar. G.J. Kesliwal. V.S. Yajurvedi. M.S. Rewat. S.K.Ganeriwal and Sangam RN.Pulmonary function test in School children. Indian J Physiology pharmacol.1985; Jan-Mar; 29(1):14-20

23. Medarov BI, Strachan P, Cohen R. Effect Of body Mass Index on Pulmonary FunctionTests.Chest. 2005; 128:171-172.

24. Chatterjee S, Mandal A. Pulmonary function studies in healthy school boys of West Bengal. Jpn J Physiol 1991; 41:797-808.

25. Chowgule RV, Shetye VM, Parmar JR.: Lung function tests in normal Indian children. Indian pediatrics 1995-Feb; 32:185-191.

26. Dickman ML, Schmidt CD, Gardner RM.: Spiro metric standards for normal children and adolescents. (ages 5 years through 18 years)Am Rev Respir dis 1971; 104: 680-687.

27. Meenakshi Sharma, Rambabu Sharma, Neelam Singh , Kusum Gaur: FEV1, FVC, FEV1 /FVC ratio in children of 7-14 years of age from Western Rajasthan. J Bangladesh Soc Physiol. 2013 June; 8(1): 37-41

28. Gundogdu Z, Eryilmaz N. Correlation between peak flow and body mass index in obese and nonobese children in Kocaeli, Turkey. Prim Care Respir J 2011; 20:4036.

29. Soundariya K, Neelambika N. Influence of anthropometric indices on pulmonary function tests in young individuals. World J Med Sci 2013; 9:15761. 